\title{
OCORRENCIA DE ADULTOS DE HEILIPUS CATAGRAPHUS GERMAR, 1824 (COLEOPTERA: CURCULIONIDAE) DANIFICANDO FRUTOS DE ABACATEIRO ( $\left.{ }^{1}\right)$
}

\begin{abstract}
ANDRE LUIZ LOURENĢāo (2), CARLOS JORGE ROSSETTO, Seção de Entomologia Fitotécnica, e NILBERTO BERNARDO SOARES (2), Seçāo de Fruticultura Tropical, Instituto Agronōmico.
\end{abstract}

\section{RESUMO}

Em dezembro de 1982, foram observados adultos de Heilipus catagraphus Germar, 1824 danificando frutos jovens de abacate em um pomar comercial localizado no distrito de Barão Geraldo, Campinas (SP). Os adultos comiam a casca e a polpa dos frutos sem atingir a semente. Posteriormente, os adultos desapareceram sem que fosse tomada qualquer medida de controle. A larva desta espécie é conhecida como broca de plantas das famflias Lauraceae e Anonaceae.

\section{INTRODUÇÃO}

Heilipus catagraphus Germar, 1824 é um besouro cujas larvas broqueiam troncos e ramos de abacateiro (Persea americana Mill.) (1, $2,3,6,9)$, canelinha (Nectandra venulosa Meissn.) $(2,3,9)$, da família Lauraceae, bem como de fruteira-do-conde (Anona reticulata L.) (2, 3, 8, 9) e biribá (11) (possivelmente Rollinia sieberi DC.), da familia Anonaceae. Existe, ainda, uma citação de ocorrência de larvas desse inseto broqueando plantas dessa última família, sem haver, contudo,

(1) Os autores agradecem ao Dr. Germano H. Rosado Neto, da Universidade Federal do Paraná, e ao Dr. Sérgio A. Vanin, da Universidade de São Paulo, a identificaçāo do inseto. Recebido para publicação a 12 de maio de 1983.

(2) Com bolsa de suplementação do CNPq. 
a citação das espécies botânicas (4). H. catagraphus foi assinalado nos Estados de Minas Gerais, Rio de Janeiro e São Paulo (12); segundo GUERIN (7), sua distribuição geográfica abrange o Centro e o Sul do País.

É possível que IHERING (8) tenha sido o primeiro a citar a ocorrência de H. catagraphus no Brasil, ao descrever, em 1910, os danos causados por suas larvas em troncos de fruteira-do-conde. Cinco anos mais tarde, BONDAR (2) relatou que essa cultura se tornava impraticável em determinadas regiōes devido ao ataque desse inseto, pois as larvas, desenvolvendo-se sob a casca de ramos e troncos, preferencialmente na região do colo, provocavam o amarelecimento e posterior morte das plantas. Também relatou ataques do inseto dessa mesma forma em abacateiro e na canelinha.

Muito pouco se sabe sobre hábitos e biologia de $\mathbf{H}$. catagraphus. Em abacateiro, foi observado que o adulto, mediante ação do rostro, faz incisões e orifícios na casca do tronco e, a fêmea, em cada orifício, deposita um ovo. As larvas se desenvolvem sob a casca, prejudicando os tecidos subcorticais da planta $(\mathbf{1}, \mathbf{9})$.

$\mathrm{Na}$ literatura referente a esse inseto, encontrou-se apenas a citação dos prejuízos decorrentes da ação das larvas, ou seja, a importância de H. catagraphus restringindo-se a uma coleobroca que danifica ramos e troncos de abacateiro, além das espécies vegetais anteriormente referidas.

Em dezembro de 1982, os autores deste trabalho observaram a presença de adultos dessa espécie alimentando-se de frutos novos de um pomar comercial de abacateiros do cultivar Fortuna, localizado no distrito de Barão Geraldo, em Campinas (SP). A infestação dos besouros era bastante desuniforme, resultando disso árvores sem nenhum fruto atacado e outras cujos frutos apresentavam áreas comidas irregularmente contornadas por uma exsudação branca. Foram também encontrados frutos com várias partes comidas pelos insetos adultos (Figura 1), que depredavam a casca e parte da polpa sem, contudo, atingir a semente. $O$ número de adultos observados era relativamente pequeno em relação aos frutos atacados. Foi constatado, no entanto, que um único inseto pode danificar vários frutos e que os adultos, quando tocados, ou assim que manuseados os frutos em que estavam presentes, deixavam-se cair ao solo, simulando morte. Para sua coleta, então, balançavam-se os ramos com frutos atacados e recolhiam-se os insetos no chão. Adultos vivos foram levados para laboratório e mantidos em gaiolas teladas colocadas sobre abacates novos, nos quais reproduziram o mesmo tipo de dano observado em campo.

$\mathrm{Na}$ América do Norte existe outra espécie do gênero Heilipus que causa danos semelhantes ao abacateiro: H, apiatus (Olivier, 1807) 

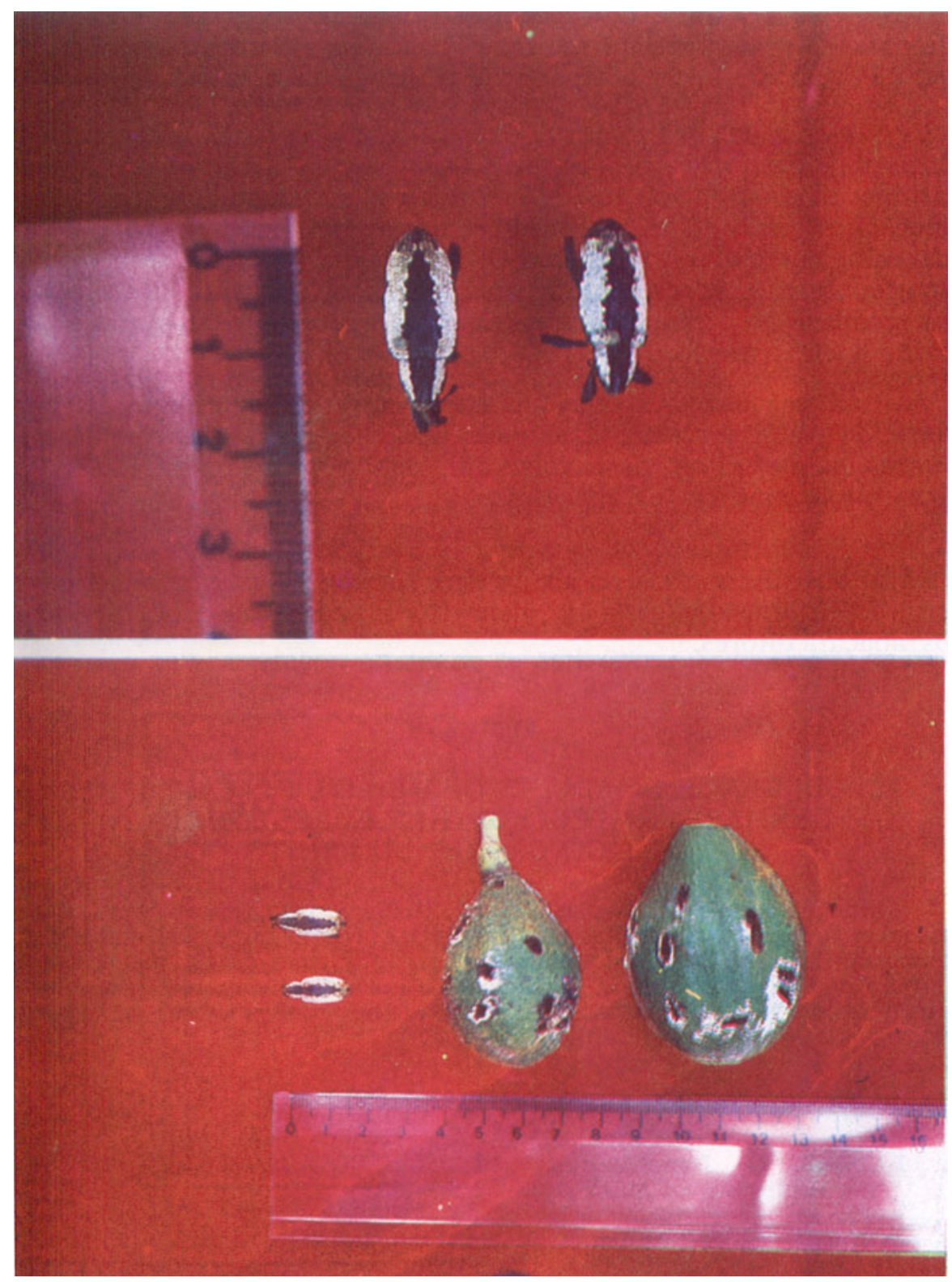

FIGURA 1 - Adultos de Heilipus catagraphus Germar, 1824 e seu dano em fruto jovem de abacate. Campinas, 1982. 
(= H. squamosus (Le Conte, 1824)) (10), cujas larvas são brocas do tronco dessa planta e cujos adultos algumas vezes são encontrados alimentando-se de frutos jovens ou de brotos e ramos novos. Esse besouro é considerado uma importante praga do abacateiro na Flórida (5).

Cerca de dois meses após a constatação de H. catagraphus no abacatal de Campinas, os adultos desapareceram, sem que fosse tomada qualquer medida de controle: seu ataque se restringiu aos frutos novos, sendo que apenas se tornaram impróprios para comercialização aqueles que sofreram lesões profundas. Os frutos que tiveram áreas comidas superficialmente apresentaram, quando completamente desenvolvidos, boa recuperação, ficando as áreas lesadas com superfície áspera e parda d̉evido à cicatrização.

É provável que essa infestação de $\mathbf{H}$. catagraphus seja proveniente do próprio pomar observado, ou de pomares vizinhos, em cujas árvores as larvas se desenvolveram, dando origem aos adultos que passaram a danificar os abacates.

A constatação de que ambas as fases, larval e adulta de $\mathbf{H}$. catagraphus são nocivas ao abacateiro, torna esta espécie relativamente mais importante do ponto de vista de praga e merecedora de atenção dos abacaticultores.

\section{SUMMARY}

\section{OCCURRENCE OF ADULTS OF HEILIPUS CATAGRAPHUS GERMAR, 1824 (COLEOPTERA :CURCULIONIDAE) DAMAGING AVOCADO FRUITS}

During December, 1982, adults of Heilipus catagraphus were observed damaging young avocado fruits in a commercial orchard in Baräo Geraldo district. Campinas, State of São Paulo, Brazil. The adults were eating the epicarp and the pulp of the fruits without damaging the seed. The larva of this species was already known in Brazil as borer of plants of the families Lauraceae and Anona ceae.

\section{REFERENCIAS BIBLIOGRAFICAS}

1. BARBOSA, C. Inimigor e moléstias. In: DO ABACATEIRO e do abacate. São Paulo, Ed. do Autor, 1933. p.276-300.

2. BONDAR, G. Bichos damninhos da fructicultura e arboricultura. São Paulo. Chácaras e Quintais, 1915. 35p. (Biblioteca Agrícola Popular Brasileira. 22)

3. COSTA LIMA, A. da. Insetos do Brasil: Coleópteros. Rio de Janeiro, Escola Nacional de Agronomia, 1956, tomo 10, p.98-99. (Série didática, 12)

4. DUARTE, F. E. Insetos holometabólicos. Agronomia, r(3):143-170, 1948. 
5. EBELING, W. Avocado pests. In: SUBTROPICAL fruit pests. California University of California, Division of Agricultural Sciences, 1959 . p.301-302

6. FONSECA, J. P. da. Relação das principais pragas observadas nos anos de 1931, 1932 e 1933, nas plantas de maior cultivo no Estado de São Paulo. Arquivos do Instituto Biológico, São Paulo, 5:263-289, 1934.

7. GUERIN, J. Coleopteros do Brasil. São Paulo, Faculdade de Filosofia. Ciências e Letras da Universidade de São Paulo, 1953. 195p.

8. IHERING, H. von. As brocas e a arboricultura. Boletim de Agricultura São Paulo, $10(6): 622-534,1910$.

9. MARICONI, F. A. M. Inseticidas e seu emprego no combate às pragas. São Paulo, Nobel, 1976. tomo 2, p.43-44.

10. O'BRIEN, C. W. \& WIBMER, G. J. Annotated check list of the weevils (Curculionidae sensu lato) of North America, Central America, and the West Indies (Coleoptera: Curculionidae). Memoirs of the American Entomological Institute, 34:1-382, 1982.

11. SCHLOTTFELDT, C. S. Insetos encontrados em plantas cultivadas e comuns Ceres, Viçosa, 6(31):52-65, 1944.

12. SIlvA, A. G. d'A. e; GONÇALVES, C. R.; GALVĀO, D. M.; GONÇALVES, A. J. L.; GOMES, J.; SILVA, M. do N. ; SIMONI, L. de. Quarto catálogo dos insetos que vivem nas plantas do Brasil, seus parasitos e predadores. Rio de Janeiro, Ministério da Agricultura, Departamento de Defesa e Inspeçāo Agropectłária, 1968 . parte 2, tomo 1, p.512. 